\title{
Distance to the closest radiotherapy facility and survival after a diagnosis of rectal cancer in Queensland
}

\section{Peter D Baade \\ PhD, MMedSc BAppSc(Hons), Senio Research Fellow \\ Paramita Dasgupta \\ $\mathrm{PhD}, \mathrm{MSc}, \mathrm{BSc}$ (Hons) Research Officer \\ Joanne F Aitken \\ PhD, MSc, BSc(Hons) Director, Cancer Registry \\ Gavin Turrell PhD, BA(Mgt/Adm) Principal Research Fellow \\ 1 Viertel Centre for Research in Cancer Control, Cance Council Queensland, Brisbane, QLD. \\ 2 School of Public Health Queensland University of Technology, Brisbane, QLD. \\ peterbaade@ cancerqld.org.au}

MJA 2011; 195: 350-354 doi: 10.5694/mjal0.11204 n Australia, colorectal cancer (CRC) is the most commonly diagnosed invasive cancer, and CRC incidence rates are among the highest in the world. ${ }^{1,2}$ Significant geographical variation in survival after CRC diagnosis has been reported across Australia, with lower survival estimates for people living outside major cities. ${ }^{3-6}$ The reasons for these rural inequalities are complex and multifaceted. ${ }^{4,7}$ Although cancer stage explains much of the variation in survival outcomes, ${ }^{8}$ urban-rural differences in survival remain after adjusting for cancer stage. ${ }^{4}$ Thus, additional factors, including access to treatment, may have an independent association with survival after CRC diagnosis.

Access to treatment services is strongly influenced by distance. Most patients with $\mathrm{CRC}$ require surgery, but adjuvant radiotherapy can be used before and after surgery to reduce recurrence and improve outcomes.9,10 For patients with rectal cancer, in particular, preoperative radiotherapy reduces the risk of local recurrence by at least half and improves disease-free survival. ${ }^{11,12}$

International studies have shown that the likelihood of patients with rectal cancer receiving radiotherapy is inversely associated with travel time to a radiotherapy facility, even after accounting for demographic, pathological and socioeconomic factors known to influence treatment patterns. ${ }^{13,14}$ Equivalent Australian data for the effect of distance from a radiotherapy facility on rectal cancer survival, after adjustment for stage, have not been reported.

We report here the association between survival outcomes (adjusted for spread of disease) and distance to the closest radiotherapy facility for people diagnosed with rectal cancer in Queensland.

\section{Methods}

\section{Study cohort}

All Qld residents aged 20-79 years who were diagnosed with invasive

Objective: To determine whether an association exists between distance from radiotherapy facilities and survival outcomes of people diagnosed with rectal cancer.

Design and setting: Descriptive population-based study using data from the Queensland Cancer Registry.

Patients: All patients aged $20-79$ years $(n=6848)$ diagnosed with invasive rectal cancer between 1 January 1996 and 31 December 2006.

Main outcome measure: Cause-specific survival.

Results: The 5-year cause-specific survival was 62\% (95\% Cl, 61\%-64\%); it was strongly influenced by stage at diagnosis (American Joint Committee on Cancer, Stages I-IV), ranging from 86\% (Stage I) to 9\% (Stage IV). After adjusting for age, sex, and stage at diagnosis, patients who lived 100-199 km, $200-399 \mathrm{~km}$ and $400 \mathrm{~km}$ or more from a radiotherapy facility were 16\%, 30\%, and $25 \%$, respectively, more likely to die from rectal cancer than patients living within $50 \mathrm{~km}$ of such a facility. On average, there was a $6 \%$ increase in mortality risk $(95 \% \mathrm{Cl}, 3 \%-8 \% ; P<0.001)$ for each $100 \mathrm{~km}$ increment in distance from the nearest radiotherapy facility. Shared frailty models showed that this association persisted after adjusting for the correlation between individual cancer patients living in the same remoteness or area-level socioeconomic status categories.

Conclusions: While centralisation of cancer treatment services has merit, our study provides evidence of a shorter survival for people with rectal cancer who live relatively far from radiotherapy facilities. It remains a priority to develop and implement policy, cultural and clinical measures to reduce the burden faced by rural and remote patients with rectal cancer.

rectal cancer (International classification of diseases, 10th edition, Australian modification [ICD-10-AM] codes C19, C20, and C21.8) between 1 January 1996 and 31 December 2006 were eligible for the study. We restricted the analysis to this age group because rectal cancer is very rare among children and teenagers, and death certification is known to be less accurate in older individuals. ${ }^{15}$ Incident cases were obtained from the Queensland Cancer Registry (QCR), a populationbased registry covering the entire state of Qld, with notifications required by law. ${ }^{16}$

\section{Survival data}

Survival data for the study cohort were examined up to 31 December 2007, thus providing at least a 1-year follow-up for each patient. For patients with multiple primary rectal cancer sites, only the site at the most advanced stage (and its associated pathological variables) was considered for our study. Survival duration was defined as time in years between diagnosis and date of death or 31 December 2007 (the study end point), whichever was earlier.

\section{Geocoding of patients' addresses}

Patients' addresses were geocoded into longitude and latitude coordinates using automatic geographical information system (GIS) software. Because of lack of precise address information, 133 patients (1.9\%) were excluded. The street addresses could be accurately geocoded for 6723 $(98.2 \%)$ of the 6848 rectal cancer records with viable address information. The remaining addresses were geocoded either to a street at the centre of the residential suburb at the time of diagnosis (110 records, $1.6 \%$ ) or to the centre of the postal code area of residence $(15,0.2 \%)$.

\section{Location of radiotherapy facilities in Queensland}

From 1996 to 2000, radiotherapy was available at two public and two private 
1 Impact of travelling distance and travel time to the nearest radiotherapy facility on cause-specific survival estimates for patients diagnosed with rectal cancer in Queensland, 1996-2006*

\begin{tabular}{|c|c|c|c|c|c|}
\hline Variable & $\begin{array}{l}\text { No. (\%) of } \\
\text { patients }\end{array}$ & $\begin{array}{l}\text { 2-year survival } \\
(95 \% \mathrm{Cl})\end{array}$ & $\begin{array}{c}\text { 5-year survival } \\
(95 \% \mathrm{Cl})\end{array}$ & $\begin{array}{l}\text { Crude hazard ratio } \\
(95 \% \mathrm{Cl})\end{array}$ & $\begin{array}{l}\text { Adjusted hazard ratio } \\
(95 \% \mathrm{Cl})\end{array}$ \\
\hline \multicolumn{5}{|l|}{ Sex } & $\chi^{2}=1.84 ; \mathrm{df}=1 ; P=0.175^{\ddagger}$ \\
\hline Women & $2455(35.8 \%)$ & $77.8 \%(76 \%-79 \%)$ & $65.2 \%(63 \%-67 \%)$ & 1.00 & 1.00 \\
\hline Men & $4393(64.2 \%)$ & $75.3 \%$ (74\%-77\%) & $60.7 \%(59 \%-62 \%)$ & 1.08 (0.99-1.19) & $1.07(0.97-1.17)$ \\
\hline \multicolumn{5}{|l|}{ Age group } & $\chi^{2}=88.19 ; \mathrm{df}=3 ; P<0.001^{\ddagger}$ \\
\hline $20-59$ years & $2361(34.5 \%)$ & $82.0 \%(80 \%-84 \%)$ & $70.1 \%(68 \%-72 \%)$ & 1.00 & 1.00 \\
\hline $60-69$ years & $2285(33.4 \%)$ & $76.0 \%(74 \%-78 \%)$ & $62.9 \%(61 \%-65 \%)$ & $1.25(1.12-1.40)$ & $1.29(1.16-1.44)$ \\
\hline 70-74 years & $1169(17.1 \%)$ & $72.5 \%(70 \%-75 \%)$ & $57.0 \%(54 \%-60 \%)$ & $1.35(1.19-1.54)$ & $1.51(1.32-1.71)$ \\
\hline 75-79 years & $1033(15.0 \%)$ & $67.5 \%(64 \%-70 \%)$ & $49.5 \%(46 \%-53 \%)$ & $1.58(1.38-1.80)$ & $1.81(1.59-2.07)$ \\
\hline \multicolumn{5}{|c|}{ Stage at diagnosis } & $\chi^{2}=1687.02 ; \mathrm{df}=4 ; P<0.001^{\ddagger}$ \\
\hline I & $1622(23.7 \%)$ & $93.5 \%(92 \%-95 \%)$ & $86.4 \%(85 \%-88 \%)$ & 1.00 & 1.00 \\
\hline$\|$ & $1470(21.5 \%)$ & $87.5 \%(86 \%-89 \%)$ & $71.8 \%(69 \%-74 \%)$ & $3.11(2.49-3.89)$ & $3.04(2.43-3.80)$ \\
\hline III & $1688(24.6 \%)$ & $76.3 \%(74 \%-78 \%)$ & $55.2 \%(53 \%-58 \%)$ & $7.17(5.84-8.81)$ & $7.27(5.92-8.94)$ \\
\hline IV & $616(9.0 \%)$ & $26.2 \%(23 \%-30 \%)$ & $9.3 \%(7 \%-13 \%)$ & $34.26(27.71-42.36)$ & $35.14(28.41-43.46)$ \\
\hline Unknown & $1452(21.2 \%)$ & $66.3 \%(64 \%-69 \%)$ & $55.1 \%(52 \%-58 \%)$ & $7.48(6.07-9.22)$ & $7.67(6.22-9.45)$ \\
\hline \multicolumn{5}{|c|}{ Distance by road from nearest radiotherapy facility } & $\chi^{2}=23.65 ; \mathrm{df}=4 ; P<0.001^{\ddagger}$ \\
\hline$<50 \mathrm{~km}$ & $4252(62.1 \%)$ & $77.9 \%(77 \%-79 \%)$ & $64.5 \%(63 \%-66 \%)$ & 1.00 & 1.00 \\
\hline $50-99 \mathrm{~km}$ & $469(6.8 \%)$ & $74.3 \%(70 \%-78 \%)$ & $60.9 \%(56 \%-65 \%)$ & $1.14(0.96-1.35)$ & $1.03(0.87-1.22)$ \\
\hline $100-199 \mathrm{~km}$ & $675(9.9 \%)$ & $74.2 \%(71 \%-77 \%)$ & $59.6 \%(55 \%-63 \%)$ & $1.18(1.02-1.36)$ & $1.16(1.00-1.34)$ \\
\hline $200-399$ km & $964(14.1 \%)$ & $73.0 \%(70 \%-76 \%)$ & $58.0 \%(55 \%-61 \%)$ & $1.29(1.14-1.45)$ & $1.30(1.15-1.47)$ \\
\hline$\geqslant 400 \mathrm{~km}$ & $488(7.1 \%)$ & $72.7 \%(68 \%-77 \%)$ & $57.4 \%(52 \%-62 \%)$ & $1.37(1.17-1.60)$ & $1.25(1.07-1.47)$ \\
\hline \multicolumn{5}{|c|}{ Travel time to nearest radiotherapy facility ${ }^{\dagger}$} & $\chi^{2}=20.43 ; \mathrm{df}=4 ; P<0.001^{\ddagger}$ \\
\hline 0-1 hour & $4517(66.0 \%)$ & $77.5 \%(76 \%-79 \%)$ & $64.3 \%(63 \%-66 \%)$ & 1.00 & 1.00 \\
\hline $1-2$ hour & $736(10.7 \%)$ & $75.6 \%(72 \%-79 \%)$ & $59.4 \%(56 \%-63 \%)$ & $1.16(1.01-1.33)$ & $1.07(0.93-1.23)$ \\
\hline 2-4 hour & 897 (13.1\%) & $72.2 \%(69 \%-75 \%)$ & $58.3 \%(55 \%-62 \%)$ & $1.26(1.11-1.43)$ & $1.28(1.13-1.45)$ \\
\hline $4-6$ hours & $624(9.1 \%)$ & $74.6 \%$ (71\%-78\%) & $58.6 \%(54 \%-63 \%)$ & $1.27(1.10-1.47)$ & $1.24(1.08-1.44)$ \\
\hline$\geqslant 6$ hours & $74(1.1 \%)$ & $65.7 \%(54 \%-75 \%)$ & $55.1 \%(42 \%-66 \%)$ & $1.51(1.05-2.17)$ & $1.22(0.85-1.76)$ \\
\hline
\end{tabular}

* Using multivariable Cox proportional hazards regression models. † Calculated using a separate model, also containing sex, age group and stage at diagnosis. ‡ Joint $\chi^{2}$ tests for model

hospitals in or near the Qld state capital, Brisbane, situated in the southeast corner of the state, and at one public hospital in Townsville, about $1300 \mathrm{~km}$ north of Brisbane. From 2001, an additional private hospital, also in the southeast corner, provided radiotherapy, as did another large public facility in Brisbane from 2002. Address details for these radiotherapy facilities were geocoded into latitude and longitude coordinates.

\section{Distances to radiotherapy facilities}

As Euclidean (straight-line) measures may underestimate travel times, ${ }^{17,18}$ we calculated actual road travel distances and times between a patient's address of usual residence and the address of the closest radiotherapy facility, using GIS applications and a street network database. These calculations were made on a year-specific basis to accommodate the increasing coverage of radiotherapy facilities over time. The distances and travel times were collapsed into categories (Box 1).

\section{Rectal cancer staging}

As with most population-based cancer registries, information on cancer stage is not routinely collected by the QCR. However, rectal cancer is one of the most amenable to stage extraction from pathology reports, and pathology stage is a reliable substitution for colorectal cancer stage reported by clinicians. ${ }^{19}$ Two clinical coders extracted details of tumour size, nodal involvement and presence of metastases (the tumour, node, metastasis [TNM] system) from pathology reports and other clinical information held by the QCR. Rectal cancer stage was assigned to each patient according to the American Joint Committee on Cancer (AJCC) and the Union for International Cancer Control evidence-based TNM system. ${ }^{20}$ AJCC Stages I-IV were derived from TNM values with Stage I cancers being the least advanced. To assess coding consistency, stage information for a sample of $5 \%$ of records $(n=347)$ was extracted by both clinical coders, with $98 \%$ agreement for TNM stage.

\section{Statistical analysis}

Cause-specific survival was used; that is, deaths attributed to rectal cancer were considered to be events, and deaths from other causes were censored. Statistical analyses were performed using Stata version 11 (StataCorp, College Station, Tex, USA).

The association between distance by road or travel time and causespecific survival was assessed using Cox proportional hazards regression. Separate models were used for distance by road and travel time to radiotherapy facilities. Estimates were adjusted by age group, sex and stage at diagnosis. Two stratified estimation 
2 Effect of distance to the nearest radiotherapy facility on survival after a diagnosis of rectal cancer in Queensland, using stratified and shared frailty models

Model

Hazard ratio $(95 \% \mathrm{Cl})$

Stratified models

Strata by stage, adjusted for sex $\quad \chi^{2}=22.44 ; \mathrm{df}=4 ; P<0.001 *$

and age group

$<50 \mathrm{~km} \quad 1.00$

$50-99 \mathrm{~km} \quad 1.04(0.87-1.23)$

$100-199 \mathrm{~km} \quad 1.16(1.00-1.34)$

$200-399 \mathrm{~km} \quad 1.30(1.15-1.46)$

$\geqslant 400 \mathrm{~km} \quad 1.24(1.06-1.45)$

Strata by age group and sex; $\quad \chi^{2}=24.18 ; \mathrm{df}=4 ; P<0.001 *$

adjusted for stage

$<50 \mathrm{~km}$

$50-99 \mathrm{~km} \quad 1.03(0.87-1.22)$

$100-199 \mathrm{~km} \quad 1.16(1.00-1.34)$

$200-399 \mathrm{~km} \quad 1.30(1.15-1.47)$

$\geqslant 400 \mathrm{~km} \quad 1.26(1.07-1.48)$

Shared frailty models (adjusted for sex, stage and age group)

Random effect $=$ ARIA+

$\theta<0.0001$ (SE $<0.0001$

$\left.\chi^{2}<0.0001 ; P=0.500\right) *$

Road distance

$\chi^{2}=23.65 ; \mathrm{df}=4 ; P<0.001^{*}$

$<50 \mathrm{~km}$

1.00

$50-99 \mathrm{~km}$

$1.03(0.87-1.22)$

$100-199 \mathrm{~km}$

$1.16(1.00-1.34)$

200-399 km

$1.30(1.15-1.47)$

$\geqslant 400 \mathrm{~km}$

$1.25(1.07-1.47)$

Random effect $=I R S D$

Road distance

$<50 \mathrm{~km}$

$\theta=0.017(\mathrm{SE}=$

$P<0.001$ )*

$\chi^{2}=11.54 ; \mathrm{df}=4 ; P=0.021^{*}$

1.00

$50-99 \mathrm{~km}$

$0.93(0.78-1.11)$

$100-199 \mathrm{~km}$

$1.06(0.91-1.23)$

200-399 km

$1.21(1.06-1.37)$

$\geqslant 400 \mathrm{~km}$

$1.13(0.96-1.34)$

ARIA + = Accessibility/Remoteness Index of Australia. IRSD = Index of Relative Socio-economic Disadvantage. $\theta=$ measure of variance for random effect. $*$ Joint $\chi^{2}$ tests for model fit.
Random effects Cox models (or shared frailty models) were also used to examine whether distance was an independent predictor of survival, after adjusting for age, sex and stage, and accounting for the correlation between individuals within the same geographical areas, as defined by remoteness (Accessibility/Remoteness Index of Australia [ARIA+] $)^{21}$ or socioeconomic disadvantage (Index of Relative Socio-economic Disadvantage [IRSD]). ${ }^{22}$ In these models, the area-level variable is included in the model as a random effect with unit mean and unknown variance; this measures the between-area variation. Larger variance estimates imply greater variability in "frailty" between areas with a greater correlation of survival times of cancer patients within the same geographical category.

\section{Ethics approval}

Ethics approval was obtained from the Behavioural and Social Sciences Ethical Review Committee, University of Queensland. Permission to access confidential data from the QCR was given by the Research Ethics and Governance Unit, Queensland Department of Health.

\section{Results}

There were a total of 6848 people in the study cohort; 4393 (64.2\%) were men (Box 1). The mean age at diagnosis was 63 years (median, 65 years; range, 20-79 years) and the mean follow-up was 4 years (median, 3 years; range, $0-12$ years). During the follow-up period, 2556 patients (37.3\%) died; 2034 (79.6\%) of these deaths were due to rectal cancer. The 5 -year overall cause-specific survival was $62 \%$ (95\% CI, 61\%-64\%).

After adjustment for the other variables in Box 1, including stage at diagnosis, there was no statistically significant evidence of a survival difference related to sex (Box 1). The risk of dying from rectal cancer increased significantly with age, with more advanced stage, and with increasing distance by road from the nearest radiotherapy facility (Box 1). Compared with patients with rectal cancer who lived within $50 \mathrm{~km}$ of a radiotherapy facility, those living 100-
$199 \mathrm{~km}, 200-399 \mathrm{~km}$ and at least $400 \mathrm{~km}$ from a radiotherapy facility were $16 \%, 30 \%$ and $25 \%$ more likely to die from rectal cancer, respectively, after adjustment for stage, sex and age group at diagnosis (Box 1).

The magnitude and significance of these effects were similar when age was treated as a continuous variable (results not shown). A separate model with road distance as a continuous variable found a significant increasing linear association (hazard ratio [HR], 1.06; 95\% CI, 1.03-1.08; $P<0.001)$ between the risk of dying and the distance (per $100 \mathrm{~km}$ ) to the nearest radiotherapy facility, after adjusting for stage, age at diagnosis and sex (full results not shown).

Estimated travel times to the closest radiotherapy faculty were also significantly associated with risk of death from rectal cancer after controlling for stage, sex and age (Box 1). Patients with travel times of 2-4 hours, 4-6 hours and 6 hours or more from the nearest radiotherapy facility had a lower survival $(22 \%-28 \%$ increased risk of death) compared with those living within an hour of a radiotherapy facility. There was a 5\% increase in risk per hour of travel when road travel time was treated as a continuous variable (HR, 1.05; 95\% CI, 1.021.07; $P<0.001)$. Almost identical results were observed when the survival analysis was repeated with stratification by stage, and then by age and sex (Box 2).

In the sensitivity analyses for unknown cancer stage, the significant association between distance to a radiotherapy facility and survival remained for each assumption made (see Statistical analysis). For example, the adjusted HRs for distances of 200 $399 \mathrm{~km}$ compared with $<50 \mathrm{~km}$ ranged from 1.25 to 1.33 for the three assumptions, with all being statistically significant $(P<0.001)$. Similar results were seen when distance was treated as a continuous variable, and also for the associations between road travel time and survival (results not shown).

The significant association between distance to a radiotherapy facility and rectal cancer survival remained after accounting for the correlation between individual cancer patients living in the same remoteness cate- 
gory (impact of distance: $\chi^{2}=23.65$; $\mathrm{df}=4, P<0.001)$ or area-level socioeconomic status category (impact of distance: $\chi^{2}=11.54 ; \mathrm{df}=4, P=0.021$ ) (Box 2). There was no evidence of a significant correlation between survival times for patients within the same remoteness category; however, there was a significant correlation between cancer patients in the same area-level socioeconomic status category. Similar results were seen when models were run with travel times to radiotherapy facilities (results not shown).

\section{Discussion}

To our knowledge, this is the first time that the association between distance to treatment centres and survival for patients with rectal cancer has been reported in Australia. Among patients with rectal cancer diagnosed in Qld, we found that, after adjusting for age group, sex and stage at diagnosis, the risk of cause-specific mortality increased by $6 \%$ for each $100 \mathrm{~km}$ increment in distance from a hospital offering radiotherapy.

The current Australian Clinical Practice Guidelines for the management and treatment of colorectal cancer recommend adjuvant preoperative or postoperative radiotherapy for high-risk (T3/4 or N1) rectal cancer, and that any postoperative adjuvant therapy program for rectal cancer should include radiotherapy and chemotherapy. ${ }^{23}$ Preoperative radiotherapy reduces the risk of local recurrence for patients with rectal cancer by at least half and improves diseasefree survival. ${ }^{11,12,24}$ Although radiotherapy services are considered to be integral to a multidisciplinary approach to treatment of patients with rectal cancer, ${ }^{10}$ the increased distances rural patients need to travel to use these services are recognised as a barrier to optimum treatment, particularly when prolonged absence from home disrupts normal life and involves financial hardship. ${ }^{25}$ International studies have shown that patients with rectal cancer who need to travel longer distances are less likely to receive radiotherapy ${ }^{13,14}$ and, consistent with this, Scandinavian patients with rectal cancer treated at local hospitals lacking radiotherapy units were found to receive radiotherapy less often and to have significantly increased rates of local recurrence. ${ }^{9,26}$ In New South Wales, patients in rural and remote areas with rectal cancer are reported to have lower radiotherapy completion rates than their urban counterparts. ${ }^{27}$

Although our study did not examine the type of treatment that patients in our cohort actually received, the results show that increasing distance from centres offering radiotherapy has a direct association with survival outcomes for patients with rectal cancer, independent of disease spread. Given that for complex treatments, such as radiotherapy, some centralisation may be inevitable, it is imperative that health services find ways to improve access when distance is a barrier. This includes realistic financial reimbursement for travel and accommodation costs incurred, and adequate outreach services to increase use of radiotherapy services when a facility is not located nearby. ${ }^{28}$

About $21 \%$ of the rectal cancer records contained insufficient information to determine cancer stage. This is a higher proportion than we found for colon cancer cases (14\%), and is slightly higher than reported in a NSW study ${ }^{29}$ and in United States data (based on Surveillance, Epidemiology, and End Results [SEER] data). ${ }^{30}$ A higher percentage of patients with unstaged rectal cancer (compared with patients with colon cancer) has been found in other studies. ${ }^{31}$ The main limitation with coding colorectal cancer stage using pathology reports is the lack of information on distant metastasis. $^{32}$ The stage-specific survival estimates in our study suggest that a large proportion of rectal cancers with unknown stage are likely to be fairly advanced at diagnosis. Using the sensitivity analyses for unknown stage, we found that the association between lower survival and increasing distance and time to reach a radiotherapy facility remained, irrespective of the assumptions made about the true distribution of cancer stages. It is possible that the broad grouping of stage into four categories could have resulted in residual confounding; however, on repeating the analysis using separate $\mathrm{T}, \mathrm{N}$ and $\mathrm{M}$ stage descriptors the results did not change.
The strengths of our study include the use of population-based cancer registry data and GIS-based estimates of travel time (and distance) derived, in most cases, from exact street addresses. The limitations include a lack of knowledge of the type of treatment received. Furthermore, distance and time calculations were based on the closest radiotherapy facility, not the actual facilities at which patients received treatment. We were not able to quantify the extent to which these differed; however, distance from these centres was independently associated with survival. Finally, in using causespecific survival, inaccuracies in cause of death coding may underestimate the true mortality attributable to the cancer.

It is possible that the association between distance from a radiotherapy facility and survival after rectal cancer is a result of currently unmeasured factors, which could relate to the demographic and socioeconomic characteristics of individuals, other clinical attributes of the cancer, or characteristics of patients' area of residence. ${ }^{33}$ This possibility is strengthened by our finding of a significant correlation between survival estimates within the same category of area-level socioeconomic status. Further research is currently underway to look at the multilevel contribution of individual factors and geographical location on survival outcomes for patients with colorectal cancer in Qld.

Acknowledgements: This study was supported by a grant from the National Health and Medical Research Council (NHMRC) (ID:561700). Peter Baade is supported by an NHMRC Career Development Fellowship (1005334). Gavin Turrell is supported by an NHMRC Senior Research Fellowship (1003710). We thank the clinical coders for extracting the cancer stage data.

Competing interests: No relevant disclosures.

Received 20 Oct 2010, accepted 18 Jan 2011.

1 Australian Institute of Health and Welfare. Australian cancer incidence and mortality (ACIM) books. Canberra: AlHW, 2009. http:// www.aihw.gov.au/cancer/data/acim_books (accessed Jul 2011).

2 Ferlay J, Shin HR, Bray F, et al. GLOBOCAN 2008 v1.2. Cancer incidence and mortality worldwide. Lyon: International Agency for Research on Cancer, 2010. (IARC CancerBase No. 10.) http:// globocan.iarc.fr/ (accessed Jul 2011).

3 Baade PD, Fritschi L, Aitken JF. Geographical differences in cancer incidence and survival in Queensland, 1996 to 2002. Brisbane: Viertel Centre for Research in Cancer Control, Queensland Cancer Fund, 2005. http:// www.cancerqld.org.au/icms_docs/60142 Geographical_differentials_in_cancer_incidence_ and_survival_in_Queensland_1996-2002.pdf (accessed Jul 2011). 
4 Jong KE, Smith DP, Yu XQ, et al. Remoteness of residence and survival from cancer in New South Wales. Med J Aust 2004; 180: 618-622.

5 Wilkinson D, Cameron K. Cancer and cancer risk in South Australia: what evidence for a rural-urban health differential? Aust J Rural Health 2004; 12: 61-66.

6 Yu XQ, O'Connell DL, Gibberd RW, et al. A population-based study from New South Wales, Australia 1996-2001: area variation in survival from colorectal cancer. Eur J Cancer 2005; 41 : 2715-2721.

7 Australian Institute of Health and Welfare Cancer in Australia 2001. Canberra: AlHW, 2004 (AlHW Cat. No. CAN 23; Cancer Series No. 28.) http://www.aihw.gov.au/publication-detail/?id= 6442467673 (accessed Jul 2011).

8 Ciccolallo L, Capocaccia R, Coleman MP, et al. Survival differences between European and US patients with colorectal cancer: role of stage at diagnosis and surgery. Gut 2005; 54: 268-273.

9 Hansen MH, Kjæve J, Revhaug A, et al. Impact of radiotherapy on local recurrence of rectal cancer in Norway. Br J Surg 2007; 94: 113-118.

10 Wolpin BM, Meyerhardt JA, Mamon HJ, Mayer RJ. Adjuvant treatment of colorectal cancer. CA Cancer J Clin 2007: 57: 168-185.

11 Sebag-Montefiore D, Stephens RJ, Steele R, et al. Preoperative radiotherapy versus selective postoperative chemoradiotherapy in patients with rectal cancer (MRC CR07 and NCIC-CTG C016): a multicentre, randomised trial. Lancet 2009; 373: 811-820.

12 Wong RK, Tandan V, De Silva S, Figueredo A. Preoperative radiotherapy and curative surgery for the management of localized rectal carcinoma. Cochrane Database Syst Rev 2007; (2) CD002102.

13 Jones AP, Haynes R, Sauerzapf V, et al. Travel time to hospital and treatment for breast, colon, rectum, lung, ovary and prostate cancer. Eur J Cancer 2008; 44: 992-999.

14 Dejardin O, Bouvier AM, Faivre J, et al. Access to care, socioeconomic deprivation and colon cancer survival. Aliment Pharmacol Ther 2008; 27: 940-949.
15 Grulich AE, Swerdlow A, dos Santos Silva l, et al. Is the apparent rise in cancer mortality in the elderly real? Analysis of changes in certification and coding of cause of death in England and Wales, 1970-1990. Int J Cancer 1995; 63: 164-168.

16 Queensland Cancer Registry, Cancer Council Queensland. Cancer in Queensland: incidence, mortality, survival and prevalence, 1982 to 2007. Brisbane: QCR, Cancer Council Queensland, 2010. http://www.cancerqld.org.au/icms_docs/60012 Cancer_in OLD - incidence_and mortality.pdf (accessed Jul 2011)

17 Schroen AT, Brenin DR, Kelly MD, et al. Impact of patient distance to radiation therapy on mastectomy in early stage breast cancer patients. J Clin Oncol 2005; 23: 7074-7080.

18 Celaya MO, Rees JR, Gibson JJ, et al. Travel distance and season of diagnosis affect treatment choices for women with early-stage breast cancer in a predominantly rural population (United States). Cancer Causes Control 2006; 17: 851-856.

19 Krnjacki LJ, Baade PD, Lynch BM, Aitken JF. Reliability of collecting colorectal cancer stage information from pathology reports and general practitioners in Queensland. Aust NZ J Public Health 2008; 32: 378-382.

20 Sobin LH, Wittekind C. TNM classification of malignant tumours (UICC). 6th ed. Hoboken, $\mathrm{NJ}$ : John Wiley and Sons, 2002

21 Australian Institute of Health and Welfare. Rural regional and remote health: a guide to remoteness classifications. Canberra: AlHW, 2004. (Cat. No. PHE 53.) http:// www.aihw.gov.au/publication-detail/?id= 6442467589 (accessed Jul 2011).

22 Australian Bureau of Statistics. Census of population and housing: socio-economic indexes for areas (SEIFA), Australia - Data only 2006. Canberra: ABS, 2008. (ABS Cat. No. 2033.0.55.001.)

23 Australian Cancer Network. Colorectal Cancer Guidelines Revision Committee. Guidelines for the prevention, early detection and management of colorectal cancer. Sydney: The Cancer Council Australia and Australian Cancer Network, 2005. http://www.nhmrc.gov.au/guidelines/ publications/cpl06 (accessed Jul 2011).

24 Holm T, Johansson H, Cedermark B, et al. Influence of hospital- and surgeon-related factors on outcome after treatment of rectal cancer with or without preoperative radiotherapy. Br J Surg 1997; 84: 657-663.

25 Martin-McDonald K, Rogers-ClarkC, Hegney D, et al. Experiences of regional and rural people with cancer being treated with radiotherapy in a metropolitan centre. Int J Nurs Pract 2003; 9: 176182

26 Olsson LI, Granström F, Glimelius B. Socioeconomic inequalities in the use of radiotherapy for rectal cancer: a nationwide study. Eur J Cancer 2011; 47: 347-353.

27 Armstrong K, O'Connell D, Leong D, et al. The NSW Colorectal Cancer Care Survey 2000. Part 1. Surgical management. Sydney: The Cancer Council NSW, 2004

28 Australian Government Department of Health and Ageing. Report of the Radiation Oncology Inquiry: a vision for radiotherapy. Canberra: $\mathrm{DoHA}$ 2002. http://www.health.gov.au/internet/main/ publishing.nsf/Content/health-roi-inquiryreport.htm (accessed Jul 2011).

29 Yu XQ, O'Connell DL, Gibberd RW, et al. Misclassification of colorectal cancer stage and area variation in survival. Int J Cancer 2008; 122: 398-402.

30 Cooper GS, Yuan Z, Stange KC, et al. The utility of Medicare claims data for measuring cancer stage. Med Care 1999; 37: 706-711.

31 Worthington JL, Koroukian SM, Cooper GS. Examining the characteristics of unstaged colon and rectal cancer cases. Cancer Detect Prev 2008; 32: 251-258.

32 Threlfall T, Wittorff J, Boutdara P, et al. Collection of population-based cancer staging information in Western Australia - a feasibility study. Popul Health Metr 2005; 3: 9

33 Kelsall HL, Baglietto L, Muller D, et al. The effect of socioeconomic status on survival from colorectal cancer in the Melbourne Collaborative Cohort Study. Soc Sci Med 2009; 68: 290-297. 